\title{
Reticulocyte Enrichment of Zinc Protoporphyrin/Heme Discriminates Impaired Iron Supply During Early Development
}

\author{
SHARON E. BLOHOWIAK, MELINDA E. CHEN, KRISTIN S. REPYAK, NICOLE L. BAUMANN-BLACKMORE, \\ DAVID P. CARLTON, MICHAEL K. GEORGIEFF, THOMAS D. CRENSHAW, AND PAMELA J. KLING
}

\author{
Departments of Pediatrics [S.E.B., M.E.C., K.S.R., N.L.B.-B., D.P.C., P.J.K.], and Animal Sciences [T.D.C.], University of Wisconsin, \\ Madison, Wisconsin 53715; Department of Pediatrics [M.K.G.], University of Minnesota, Minneapolis, Minnesota 55455
}

\begin{abstract}
In infants and children, elevated whole blood zinc protoporphyrin/heme $(\mathrm{ZnPP} / \mathrm{H})$ measures iron-deficient (ID) erythropoiesis. Because immature erythrocytes are less dense than mature erythrocytes, we hypothesized that the sensitivity of $\mathrm{ZnPP} / \mathrm{H}$ is improved if measured in the least dense cells. Blood was collected from control suckling, mildly and severely ID suckling rats. Cord blood was collected after uncomplicated pregnancies (control), diabetic pregnancies (severe ID) and after pregnancies at-risk for iron deficiency (mild ID). ZnPP/H was measured before and after a two-step density centrifugation to obtain the lightest $6.25 \%$ of erythrocyte (top fraction). The difference between whole blood and top fraction was defined as $\Delta \mathrm{ZnPP} / \mathrm{H}$. In rats, although the whole or top $\mathrm{ZnPP} / \mathrm{H}$ differed by postnatal age, $\Delta \mathrm{ZnPP} / \mathrm{H}$ was greatest after the interval with least body iron accrual. In either rats or humans with mild ID, whole blood $\mathrm{ZnPP} / \mathrm{H}$ was similar to, but $\Delta \mathrm{ZnPP} / \mathrm{H}$ was greater than controls. In rats and newborn humans, $\Delta \mathrm{ZnPP} / \mathrm{H}$ is more sensitive than whole blood $\mathrm{ZnPP} / \mathrm{H}$ in identifying conditions associated with impaired erythrocyte iron delivery and may become a useful tool in measuring erythrocyte iron incorporation in early development. (Pediatr Res 64: 63-67, 2008)
\end{abstract}

$\mathrm{T}$ here is need for a sensitive clinical index of iron-deficient (ID) erythropoiesis in growing premature infants. In premature infants, clinical practices, such as conservative transfusion criteria and erythropoietin therapy may deplete tenuous iron stores (1-4). When iron supply is limited, zinc replaces iron in the protoporphyrin IX ring to form zinc protoporphyrin (ZnPP) (5). An increased ratio of whole blood ZnPP-to-heme $(\mathrm{ZnPP} / \mathrm{H})$ reflects impaired erythrocyte iron incorporation $(5,6)$. In older infants, whole blood zinc protoporphyrin/heme $(\mathrm{ZnPP} / \mathrm{H})$ is a more sensitive indicator of early, preanemic iron deficiency than $\mathrm{Hb}$ or ferritin (7). Whole blood $\mathrm{ZnPP} / \mathrm{H}$ from cord blood or ill newborns also reflects iron status $(4,8)$. $\mathrm{ZnPP} / \mathrm{H}$ is higher in newborns born small for dates and offspring of mothers with insulin-treated diabetes (IDM), two conditions commonly exhibiting severely impaired tissue iron content, i.e., severe iron deficiency (severe ID) at birth $(4,8)$. In premature infants, whole blood $\mathrm{ZnPP} / \mathrm{H}$ falls in response to iron therapy (9) or with indirect delivery of iron via transfu-

Received July16, 2007; accepted February 20, 2008.

Correspondence: Pamela J. Kling, M.D., Meriter Hospital, 202 S. Park Street, 6 Center, Department of Pediatrics, University of Wisconsin, Madison, WI 53715; e-mail: pkling@wisc.edu

This work was supported by NIH M01 RR03186 from UW GCRC/CReFF (P.J.K.), the University of Wisconsin Women in Science and Engineering Life Cycle Grant (P.J.K.), Thrasher Research Fund (P.J.K.), and NIH R01-HD-29421 (M.K.G.)

Supplemental material available online at www.pedresearch.org. sion (3). In premature infants, whole blood ratios are inversely related to gestation (8), a clinical disadvantage because of gestation-based normal values are necessary to guide interpretation $(4,8-10)$.

In mild ID, when $\mathrm{Hb}$ levels have not yet fallen, employing a more sensitive test of iron incorporation would be useful to facilitate earlier treatment. When iron demands are great and iron is limited, testing the iron status of reticulocytes, the most recently produced erythrocytes, would decrease the number of false negative assessments and improve the sensitivity of $\mathrm{ZnPP} / \mathrm{H}$ to detect impaired iron incorporation. Previous work supports that measuring iron incorporation into reticulocytes (reticulocyte $\mathrm{Hb}$, or percent hypochromic reticulocytes) with clinical flow cytometry-based automated hematology analyzers is able to identify mild ID $(1,8,11-15)$. Although powerful, sophisticated instrumentation to investigate these parameters is not universally available. However, immature erythrocytes can also be separated based on density centrifugation. After centrifugation, the lighter (top) fraction contains greater relative numbers of reticulocytes than is seen in whole blood. Employing this low tech approach, we sought to examine whether reticulocyte enrichment via differential centrifugation (16) would allow us to examine the clinical utility of the difference between whole blood and top fraction $\mathrm{ZnPP} / \mathrm{H}$, i.e., the $\Delta \mathrm{ZnPP} / \mathrm{H}$. Because rats are used to model erythropoiesis, are more immature than term humans, and use iron for rapid growth and exhibit differences in $\mathrm{ZnPP} / \mathrm{H}$ based on iron status (17), the rat model may have utility in assessing whole blood, top fraction, and $\Delta \mathrm{ZnPP} / \mathrm{H}$. Compared with humans, the rats exhibit an exaggerated reticulocytosis, but this characteristic can be exploited by shortening the duration of experimentallyinduced mild ID necessary to assess a response. Because whole blood $\mathrm{ZnPP} / \mathrm{H}$ has been shown to respond to iron treatment in humans (9), it is feasible that whole blood, top fraction, and $\Delta \mathrm{ZnPP} / \mathrm{H}$ would also be responsive to iron treatment in newborn rats.

We hypothesized that $\mathrm{ZnPP} / \mathrm{H}$ measured in the least dense erythrocytes is reproducible and that $\Delta \mathrm{ZnPP} / \mathrm{H}$ is more sensitive in detecting mild ID than whole blood $\mathrm{ZnPP} / \mathrm{H}$ during early rat and human development.

Abbreviations: IDM, offspring of diabetes; mild ID, mild iron deficiency; mild ID+Fe, mild ID with oral iron; severe ID, severe iron deficiency anemia; $\mathbf{Z n P P / H}$, zinc protoporphyrin/heme 


\section{MATERIALS AND METHODS}

Animals. Sprague-Dawley dams (Charles River Laboratories, Wilmington, MA) and pups were studied. UW Animal Care and Use Committee approved the study. Dams were fed Harlan Teklad basic rodent diet, \#8604, with 325 $\mathrm{mg} / \mathrm{kg}$ iron in the diet. Control pups with litter size of 10 defined normal developmental $\mathrm{ZnPP} / \mathrm{H}$ ratios. In the developmental studies, rats were examined at postnatal day (P): P1 newborn, P4 suckling, P8 suckling, P12 suckling, P18 weanling and adults $(10-15 \mathrm{wk})$.

Control pups were used to develop normative values for $\mathrm{ZnPP} / \mathrm{H}$. For treatment studies, a subset of rats underwent randomization to dam-fed (but handled daily) or experimental manipulation with an artificial cow milk-based formula with insufficient iron to meet the needs of suckling rats, $4 \mathrm{mg} / \mathrm{L}$ elemental iron using ferrous sulfate. Formula-fed rats were removed from the dam and artificially fed by gastrostomy in temperature-controlled pint-sized polypropylene deli cups as previously described $(17,18)$. Feeds were adjusted to maintain daily weight gain equal to dam-fed rats with a litter size of 10 . Artificial feeding began at P4 for severe ID with anemia or P8 for mild ID without anemia. An additional group, mild ID $+\mathrm{Fe}$, included artificial feeding beginning at P8 supplemented with a once daily dose of $6 \mathrm{mg} \mathrm{kg}^{-1}$ oral ferrous sulfate (Fer-In-Sol, Mead Johnson, Evansville, IN). Formula groups were compared with dam-fed control and killed at P12.

Blood analysis and body iron determination. Rats from both developmental and treatment groups were randomly selected for either blood analysis or body iron determination. In the blood group, after lethal isofluorane anesthesia, blood was drawn via cardiac puncture and placed into EDTA. For rats assigned to body iron determination, no blood was drawn. Midline incision was performed and gastrointestinal tract was removed from the body to remove iron not yet absorbed, but residing within the gastrointestinal lumen. Blood lost during the gastrointestinal harvest was included with the body. The body without gastrointestinal tract was analyzed for iron content by atomic absorption after nitric acid/perchloric acid digestion. Briefly, the bodies were predigested for $24-48 \mathrm{~h}$ at RT in $30 \mathrm{~mL}$ concentrated nitric acid and then transferred to Teflon digest tubes with an additional $10 \mathrm{~mL}$ of concentrated perchloric acid. The samples were digested at $90^{\circ} \mathrm{C}$ for $1.5 \mathrm{~h}$, then $200^{\circ} \mathrm{C}$ until digests were clear. Total $\mathrm{Fe}$ concentration of the digests was measured, with accompanying ferrous nitrate reference standards on a Perkin Elmer 2280 Atomic Absorption Spectrophotometer (Waltham, MA).

Human participants. Cord blood samples from four separate groups of newborns were analyzed. EDTA-anticoagulated cord blood is normally collected at all deliveries in the Birthing Center at Meriter Hospital, Madison, WI and held for $7 \mathrm{~d}$ in the Blood Bank. We obtained the blood just before samples were to be discarded. Blood was obtained between June 2005 and December 2006. The term control group was randomly collected from normal term deliveries. The second group, severe ID, was identified by Nursery Intensive Care Unit (NICU) admission, from term/near-term deliveries with IDM during pregnancy, because of the marked risk for abnormal iron status in IDMs severely affected by maternal disease $(4,8)$. The third, mild ID group was a subset of larger that was identified for being at-risk for maternal iron deficiency. From the larger at-risk group, we identified a subset with normal cord whole blood $\mathrm{ZnPP} / \mathrm{H}$ (10), but cord plasma ferritin values in the lowest quartile in our lab, and called this group the mild ID group. The fourth, premature group included cord blood from newborns with birth weight less than $1500 \mathrm{~g}$, but without fetal conditions known to impair iron status, such as maternal diabetes or growth restriction. Because cord $\mathrm{ZnPP} / \mathrm{H}$ ratios in premature normally fall as gestation increases $(4,8)$, this group was included to determine whether $\Delta \mathrm{ZnPP} / \mathrm{H}$ is observed in premature newborns. The premature and IDM groups were identified from the Meriter Hospital NICU admission log and the at-risk group from the healthy newborn admission log. No other data were collected from these mother-child dyads. Approvals from the UW-Madison Human Subjects Committee and Meriter Hospital Institutional Review Board were obtained to analyze deidentified samples.

Laboratory methods. $\mathrm{ZnPP} / \mathrm{H}$ was determined before (whole blood) and after (top) the density centrifugation step. Samples were tested for clots, stored at $4^{\circ} \mathrm{C}$, and hematology profile performed by a Coulter MD Coulter Counter, (Coulter-Beckman, Hialeah, FL). An aliquot of whole blood was centrifuged in a $500 \mu \mathrm{L}$ microcentrifuge tube (Fisher Scientific, Hampton, $\mathrm{NH}$ ) at $800 \mathrm{~g}$ in an Eppendorf, 5415D Microcentrifuge (Eppendorf AG, Hamburg, Germany) for 4 min. Plasma was removed. The cell pellet was rinsed in PBS three times to remove interfering pigments (19). After rinsing, packed red blood cells were diluted 1:1 with PBS and whole blood $\mathrm{ZnPP} / \mathrm{H}$ determined with a front-face hematofluorometer (Aviv Biomedical, Lakewood, NJ).

To obtain $\mathrm{ZnPP} / \mathrm{H}$ from the top fraction, or least dense, immature erythrocytes, we used the principle of density gradient centrifugation $(11,16,20)$. We centrifuged an aliquot of whole blood for $30 \mathrm{~min}$ at $1500 \mathrm{~g}(16)$ in a 400 $\mu \mathrm{L} 8 \times 48 \mathrm{~mm}$ microcentrifuge tube (Fisher Scientific, Waltham, MA) in an

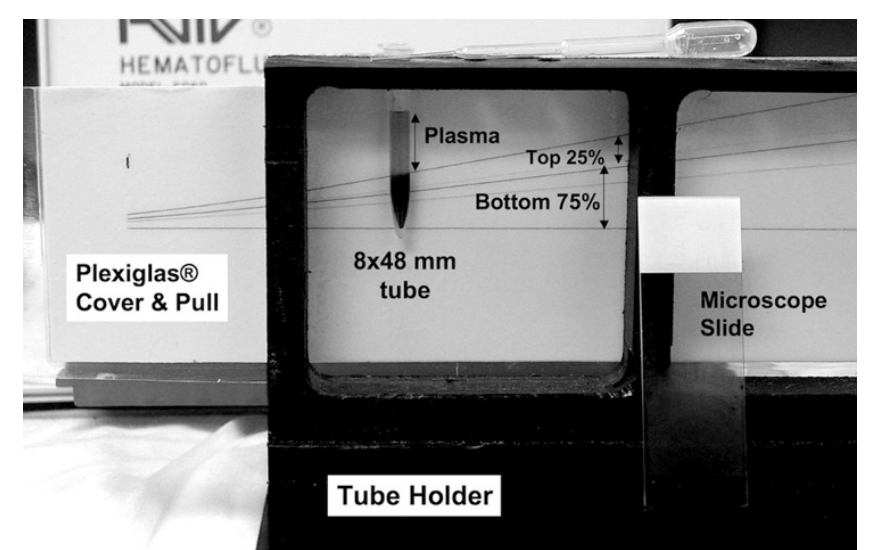

Figure 1. Polyethylene tube reader and sample. The $8 \times 48 \mathrm{~mm}$ microhematocrit tube is shown with arrows indicating plasma, top $25 \%$ of packed cells and bottom $75 \%$ of packed cells. The Plexiglas cover and pull are indicated. A microscope slide is included to show size.

Eppendorf, 5415D Microcentrifuge. Plasma was removed with a Fisherbrand gel loading pipet tip (Fisher Scientific) and set aside. The top 25\% of packed cells was identified using a custom-made polyethylene Tube Reader (Fig. 1). The top $25 \%$ of cells were transferred to a new $8 \times 48 \mathrm{~mm}$ tube, an equal volume of plasma added, and centrifugation repeated. The top $25 \%$ of these cells were transferred to a new tube, resulting in the lightest $6.25 \%$ of cells from the original sample and this was defined as the top fraction. After rinsing three times, the top fraction $\mathrm{ZnPP} / \mathrm{H}$ was measured. $\Delta \mathrm{ZnPP} / \mathrm{H}$ was defined as the difference between the top fraction and the whole blood $\mathrm{ZnPP} / \mathrm{H}$.

The Tube Reader was custom-manufactured by UW-Madison Biomedical Engineering students as a team project. The Tube Reader was $4.7 \times 2.4 \times 2.0$ $\mathrm{cm}(12 \times 6 \times 5$ in $), \mathrm{L} \times \mathrm{W} \times \mathrm{H}$ manufactured in static dissipative ultra-high molecular weight polyethylene with placeholders drilled for $8 \times 48 \mathrm{~mm}$ microcentrifuge tubes. The laminated scale was placed behind a Plexiglas window and adjusted to match each tubes packed cell volume (Figs S1-S3, Table S1, supplemental materials online at www.pedresearch.org).

An aliquot of blood obtained before reticulocyte enrichment was stained for manual reticulocyte percentage with the supravital new methylene blue stain (Sigma Chemical Co., St. Louis, MO). Reticulocyte percentage was also obtained on an aliquot of the top fraction (top 6.25\% of cells) after reconstitution with plasma. One of two different blinded reviewers determined the reticulocyte percentage by counting 1000 cells (500 on each of 2 different smears) at $100 \times$ power.

Data analysis. Sample size was determined to be eight per group for P12 control and mild ID rats assuming $80 \%$ power, $p$ value $<0.05$, to measure a $50 \mu \mathrm{mol} / \mathrm{mol}$ rise in $\mathrm{ZnPP} / \mathrm{H}$ with top fractionation. For humans, nine per group were estimated, with $80 \%$ power, $p$ value $<0.05$. Top $\mathrm{ZnPP} / \mathrm{H}$ from aliquots of the same sample within-day and between-day were examined by repeated measures ANOVA. Paired, unpaired $t$ testing, Kruskal-Wallis, or factorial ANOVA, with Fisher's post hoc testing was used. Values reported are mean \pm SEM

\section{RESULTS}

Reproducibility of top fraction $\mathrm{ZnPP/H}$. The minimal initial sample volume necessary for top fraction $\mathrm{ZnPP} / \mathrm{H}$ was 300 $\mu \mathrm{L}$. Consistent with the literature $(19,21,22)$, we previously showed that aliquots of whole blood $\mathrm{ZnPP} / \mathrm{H}$ assayed withinor between-days for up to 10 subsequent days were similar (23). If stored at $4^{\circ} \mathrm{C}$, aliquots assayed for top fraction $\mathrm{ZnPP} / \mathrm{H}$ were also similar via repeated measures ANOVA in human and rat samples within-days or between-days for $10 \mathrm{~d}$. Multiple aliquots of the same sample assayed four times on the same day for top fraction $\mathrm{ZnPP} / \mathrm{H}$ were similar $\left(n=9, F_{8,24}=1.52\right)$, $p=0.23$. Multiple aliquots of the same sample assayed over three different days for top fraction $\mathrm{ZnPP} / \mathrm{H}$ were similar $\left(n=9, F_{8,16}=0.755\right), p=0.48$. Mean coefficient of variation on individual repeated samples was $9.6 \%$ 
(range $1.4-26 \%)$. In a subset of $\mathrm{P} 4$ rats $(n=4)$, we determined whether sample processing produced an artifactual elevated $\mathrm{ZnPP} / \mathrm{H}$ by examining the heaviest fraction $\mathrm{ZnPP} / \mathrm{H}$. P4 rats were selected because these rats exhibited the greatest $\Delta \mathrm{ZnPP} / \mathrm{H}$ (greatest difference between whole blood $\mathrm{ZnPP} / \mathrm{H}$ and top $\mathrm{ZnPP} / \mathrm{H})$. We observed no difference between $\mathrm{ZnPP} / \mathrm{H}$ from the heaviest $75 \%$ (103.5 $\mu \mathrm{mol} / \mathrm{mol})$ and whole blood $\mathrm{ZnPP} / \mathrm{H}(94.0 \mu \mathrm{mol} / \mathrm{mol})$, but the lightest top $6.25 \%$ fraction was higher $(228 \mu \mathrm{mol} / \mathrm{mol}), p<0.002$.

Developmental differences in $\mathrm{ZnPP} / \mathrm{H}$ and utility of $\triangle \mathrm{ZnPP} / \mathrm{H}$ in newborn rats. In normative data from the rat developmental study, whole blood or top fraction $\mathrm{ZnPP} / \mathrm{H}$ differed by postnatal age (Fig. 2). The top fraction $\mathrm{ZnPP} / \mathrm{H}$ was higher than whole blood $\mathrm{ZnPP} / \mathrm{H}$ at all ages, except in adult rats, with top and whole blood being similar. $\Delta \mathrm{ZnPP} / \mathrm{H}$, body iron concentration $\left(\mu \mathrm{g} \mathrm{g}^{-1}\right)$, body weight $(\mathrm{g})$, daily body Fe increment $\left(\mu \mathrm{g} \mathrm{d}^{-1}\right)$ and mean reticulocyte percentages (whole/top fraction) differed over development, shown in the table inset within Figure 2. Suckling and weanling rats exhibited higher $\Delta \mathrm{ZnPP} / \mathrm{H}$ than adult rats. However, $\Delta \mathrm{ZnPP} / \mathrm{H}$ in suckling and weanling rats was similar to each other, except at P4, when higher ratios accompany the lowest daily body increment and greatest fall in body iron concentration (Fig. 2).

As anticipated, mean $\mathrm{Hb}$ and mean body iron concentration in P12 rats with longstanding severe ID were lower than controls, mild ID, or mild ID + Fe (Fig. 3). Because whole blood $\mathrm{ZnPP} / \mathrm{H}$ in $\mathrm{P} 12$ rats with severe ID was markedly higher than controls, the top fraction or $\Delta \mathrm{ZnPP} / \mathrm{H}$ was not studied. $\mathrm{Hb}$ values and $\mathrm{ZnPP} / \mathrm{H}$ in $\mathrm{P} 12$ rats with mild ID and mild $\mathrm{ID}+\mathrm{Fe}$ were similar to controls. However, the top fraction or $\Delta \mathrm{ZnPP} / \mathrm{H}$ allowed sufficient discrimination of the lower body iron content seen in mild ID, compared with controls or mild

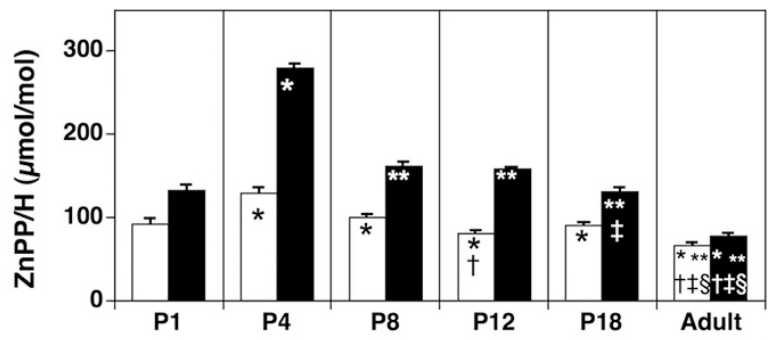

\begin{tabular}{|c|c|c|c|c|c|c|}
\hline Delta ZnPP/H & 40.3 & $149.5^{*}$ & $62.2^{* *}$ & $68.5^{* *}$ & $41.1^{* *}$ & $11.7^{* * \dagger \neq \S ~}$ \\
\hline Body Fe, $\mu \mathrm{g} / \mathrm{g}$ & 60.6 & $48.9^{*}$ & $37.4^{\star \star \star}$ & $37.3^{\star \star *}$ & $28.4^{* \star *} \dagger \ddagger$ & 38.3est \\
\hline Mean rat weight, $\mathrm{g}$ & 7.04 & $10.5^{*}$ & $18.8^{*}$ & $23.1^{\star \star * \star} \dagger$ & $36.9^{* \star \star} \dagger \ddagger$ & --- \\
\hline Body Fe gain, $\mu \mathrm{g} / \mathrm{d}$ & ---- & 8.1 & $63.8^{* *}$ & $48.5^{* *} \dagger$ & $30.4^{* *} \dagger$ & ---- \\
\hline Whole Retics \% & 74.9 & 42.9 & 13.1 & 25.8 & 17.8 & 7.7 \\
\hline Top Retics \% & $78.0 *$ & $55.5 *$ & $45.1 \%$ & $37.8 *$ & $24.0 *$ & $12.7 *$ \\
\hline
\end{tabular}

Figure 2. Whole blood (white) and top (black) $\mathrm{ZnPP} / \mathrm{H}$ in $\mathrm{P} 1$ newborn ( $n=$ $14), \mathrm{P} 4$ suckling $(n=13), \mathrm{P} 8$ suckling $(n=14), \mathrm{P} 12$ suckling $(n=15), \mathrm{P} 18$ weanling $(n=11)$, and adult rats $(n=10)$. Whole blood and top $\mathrm{ZnPP} / \mathrm{H}$ differ by postnatal age as shown in the figure, $p<0.0001$. In the inset table, $\Delta \mathrm{ZnPP} / \mathrm{H}$, body Fe concentration, rat weight, body iron increment also differ by postnatal age, $p<0.0001$. Normal body iron for adult rats was estimated (est) based on $\mathrm{Hb}$ and that $75 \%$ of body iron is contained in $\mathrm{Hb}$. For each individual measurement in the figure or table, post hoc comparisons are shown, with values differing from $\mathrm{P} 1$ indicated by $*$, from $\mathrm{P} 4$ by **, P8 by $\dagger$, $\mathrm{P} 12$ by $\ddagger$, and $\mathrm{P} 18$ by $\S, p<0.05$. In the bottom two rows of the table, reticulocyte (retics) percentages in each group rose, showing an enhancement of immature erythrocytes, as indicated by the star $(*), p<0.05$.

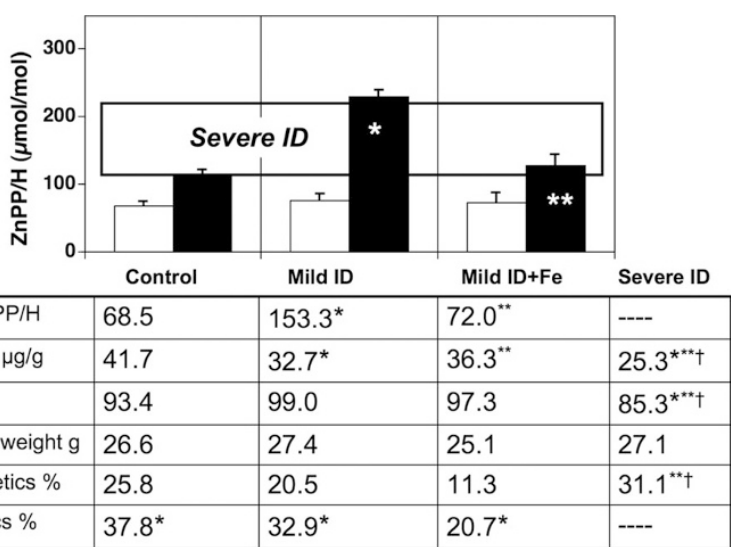

Figure 3. Whole blood (white) and top fraction (black) $\mathrm{ZnPP} / \mathrm{H}$ in $\mathrm{P} 12$ rats control rats $(n=14)$, rats with mild ID $(n=7)$, or rats with mild ID $+\mathrm{Fe}(n=$ $8)$. Mean \pm 2 SD whole blood $\mathrm{ZnPP} / \mathrm{H}$ in severe ID $(n=15)$, shown in the horizontal white box, differed from control, $p<0.0001$. Note that dam-fed P12 controls were handled daily and are not the same rats described in the unmanipulated developmental study above. $\Delta \mathrm{ZnPP} / \mathrm{H}$ and body $\mathrm{Fe}$ concentration differed by treatment, $p<0.005$, but rat weight was similar. Top and $\Delta \mathrm{ZnPP}$ discriminate mild ID from control and mild ID $+\mathrm{Fe}$. For each individual measurement on the figure or table, post hoc comparisons are shown, with values differing from control indicated by *, from mild ID by **, and mild ID $+\mathrm{Fe}$ by $\dagger, p<0.05$. In the bottom two rows of the table, reticulocyte (retics) percentages in each group rose, showing an enhancement of immature erythrocytes, as indicated by the star $(*), p<0.05$.

ID + Fe (Fig. 3). Mean reticulocyte percentages (whole/top fraction) are also shown in the table inset within Figure 3.

Developmental differences in $\mathrm{ZnPP} / \mathrm{H}$ and utility of $\Delta Z \mathbf{n P P} / \mathrm{H}$ in human cord blood. In healthy term newborns, there was no difference between whole and top fraction $\mathrm{ZnPP} / \mathrm{H}$. In human premature newborns without conditions associated with impaired iron status, whole blood and top fraction $\mathrm{ZnPP} / \mathrm{H}$ was higher than control term newborns, but no difference between whole and top fraction (Fig. 4). Whole blood $\mathrm{ZnPP} / \mathrm{H}$ in mild ID was similar to control, but $\Delta \mathrm{ZnPP} / \mathrm{H}$

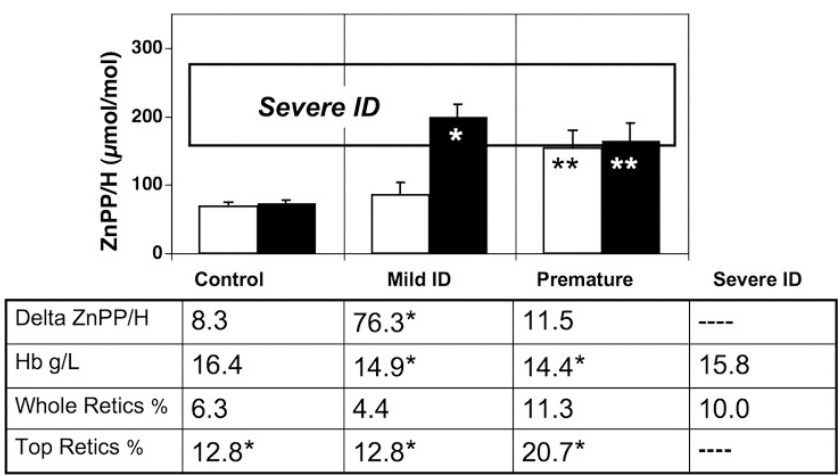

Figure 4. Whole blood (white) and top fraction (black) $\mathrm{ZnPP} / \mathrm{H}$ in cord blood of control $(n=12)$ and mild ID $(n=8)$. Mean $\pm 2 \mathrm{SD}$ whole blood $\mathrm{ZnPP} / \mathrm{H}$ in severe ID $(n=11)$ is shown in the white box, differs from control, $p<$ 0.0001 . Although whole blood $\mathrm{ZnPP} / \mathrm{H}$ is similar, $\Delta \mathrm{ZnPP} / \mathrm{H}$ is greater in mild ID, compared with controls, $p<0.001$. Although whole blood $\mathrm{ZnPP} / \mathrm{H}$ in premature infants is greater than in controls, $\Delta \mathrm{ZnPP} / \mathrm{H}$ is similar to controls. For each individual measurement on the figure or table, post hoc comparisons are shown, with values differing from control indicated by $*$, and from mild ID by **, $p<0.05$. In the bottom two rows of the table, reticulocyte (retics) percentages in each group rose, showing an enhancement of immature erythrocytes, as indicated by the star $(*), p<0.05$. 
in mild ID was higher than controls (Fig. 4). Whole blood $\mathrm{ZnPP} / \mathrm{H}$ from the severe ID group (IDM group) known for risk of tissue iron depletion was higher than control term newborns. Mean reticulocyte percentages (whole/top fraction) and mean $\mathrm{Hb}$ values are also shown in the table inset within Figure 4.

\section{DISCUSSION}

This is the first study to show that measuring $\mathrm{ZnPP} / \mathrm{H}$ in the least mature erythrocytes from newborn rats or humans improves the sensitivity of $\mathrm{ZnPP} / \mathrm{H}$ to detect impaired iron delivery. Although examining top fraction $\mathrm{ZnPP} / \mathrm{H}$ is informative, examining $\Delta \mathrm{ZnPP} / \mathrm{H}$ removes overlaps between normal and abnormal and lessens the developmental differences in newborn rats and humans. Whole blood $\mathrm{ZnPP} / \mathrm{H}$ was previously shown to measure erythrocyte iron incorporation in umbilical cord blood and NICU neonates $(3,4,8)$. $\mathrm{ZnPP} / \mathrm{H}$ is elevated in conditions known to exhibit impaired tissue iron, including IDMs. Erythrocytes circulate for up to $90 \mathrm{~d}$ in newborns (24). With maturation, erythrocytes progressively increase in density (25). Reticulocytes, the most immature erythrocytes, are identifiable by supravital staining of retained cytoplasmic RNA, mitochondria, ribosomes, centriole, and Golgi bodies (26). Reticulocyte enrichment has been described for years, including Percoll-Renografin gradients, phthalate ester separation, silicone oil gradients, and employing high-speed/longer duration floor model centrifuges for density separation $(11,16,20,25)$. With these complex methods, the least dense cells immature cells can be concentrated up to 10 times, using reticulocyte percentages as indicators. We selected a simpler, lower speed centrifugation using universally accessible microcentrifuges to accommodate small (300 $\mu \mathrm{L})$ sample volumes. Although other low density immature erythrocytes remain in the top fraction and contribute to the top fraction $\mathrm{ZnPP} / \mathrm{H}$, we measured reticulocytes to indicate separation $(16,20,25)$ because reticulocytes were sufficiently higher (doubled).

In the rat developmental study, normative data show that $\mathrm{ZnPP} / \mathrm{H}$ changes with postnatal age, but the highest $\mathrm{ZnPP} / \mathrm{H}$ and largest $\Delta \mathrm{ZnPP} / \mathrm{H}$ after virtually no net 4 -d body iron accretion. This observation supports our previous published data showing limited erythrocyte iron delivery in normal rats dam-fed at P4-P6 (17). It is unclear why normal newborn rats experience apparently insufficient iron delivery at P4. However, because growth is inversely proportional to litter size, it is possible that experimental culling of 12-14/litter to 10/litter, allows pup growth to exceed the pup's ability to mobilize sufficient iron. The relatively lower $\mathrm{ZnPP} / \mathrm{H}$ and $\Delta \mathrm{ZnPP} / \mathrm{H}$ at P8, P12, and P18 accompanied increased iron accretion. Because adult rats exhibited the lowest $\Delta \mathrm{ZnPP} / \mathrm{H}$, our data support that the relatively higher $\Delta \mathrm{ZnPP} / \mathrm{H}$ in normal developing rats could be the relative faster growth rate and greater iron needs for erythropoiesis, compared with developing humans. For rats in the treatment studies, $\mathrm{Hb}$ and body iron levels confirm the presence of mild or severe ID. Severe ID rats exhibited relatively higher whole blood $\mathrm{ZnPP} / \mathrm{H}$, but ratios in control, mild ID or mild ID $+\mathrm{Fe}$ rats were similar.
The advantage of $\Delta \mathrm{ZnPP} / \mathrm{H}$ is to discriminate a difference between untreated mild ID from control and mild ID $+\mathrm{Fe}$.

In healthy newborns, we anticipated and observed no appreciable $\Delta \mathrm{ZnPP} / \mathrm{H}$, reflecting normal fetal erythropoiesis at term. The severe ID (IDM) group was included to demonstrate that $\Delta \mathrm{ZnPP} / \mathrm{H}$ is unnecessary when whole blood $\mathrm{ZnPP} / \mathrm{H}$ is markedly abnormal. In two-thirds of IDM, impaired transferrin receptor-mediated iron transport in placenta, fetal hypoxia, exaggerated growth, and exaggerated erythropoiesis $(8,23,27)$ result in impaired tissue iron. In IDM, either $\mathrm{ZnPP} / \mathrm{H}$ $(4,8)$ or erythrocyte protoporphyrin $(28)$ were correlated with disturbed iron status, and to surrogates of maternal glycemic control $(23,28)$. From mothers at-risk for iron deficiency, we defined the mild ID group as the subset with the lowest quartile plasma ferritin levels, but normal whole blood $\mathrm{ZnPP} / \mathrm{H}$. In cord blood, using $\Delta \mathrm{ZnPP} / \mathrm{H}$ improved the sensitivity of $\mathrm{ZnPP} / \mathrm{H}$ to detect mild ID. Previous work shows that whole blood $\mathrm{ZnPP} / \mathrm{H}$ is inversely related to gestation $(4,8)$, but $\Delta \mathrm{ZnPP} / \mathrm{H}$ does not require gestation-based normals. We examined premature infants to show that, although whole blood $\mathrm{ZnPP} / \mathrm{H}$ was higher than at term, absence of appreciable $\Delta \mathrm{ZnPP} / \mathrm{H}$ supports normal fetal erythropoiesis.

Other potential clinical indicators of iron status in newborns have been investigated. A soluble truncated transferrin receptor, used in older patients, was more strongly correlated with erythropoiesis than iron indices in newborns (29-31). Interpretation of erythrocyte indices, including mean corpuscular volume and red cell distribution width, is more difficult in the newborn, due to developmentally higher mean corpuscular volume and red cell distribution width in newborns, making these measures less informative in the newborn (32). Reticulocyte indices (reticulocyte $\mathrm{Hb}$ or percent hypochromic reticulocytes), available on newer clinical flow cytometer analyzers, are effective at identifying preanemic mild ID in infants $(1,8,15)$. Although measuring different characteristics of the erythrocyte, in studies reporting both reticulocyte $\mathrm{Hb}$ and $\mathrm{ZnPP} / \mathrm{H}$, results are comparable when diagnosing ID versus normal erythropoiesis $(13,14)$ in children. Although our method was designed for simple nonautomated hematofluorometers, a channel measuring reticulocyte $\mathrm{ZnPP} / \mathrm{H}$ could be also developed for automated clinical flow cytometry analyzers, as suggested by Labbé and Dewanji (33).

Because reticulocyte indices are not universally available, whole blood $\mathrm{ZnPP} / \mathrm{H}$ is simple, cost-effective, and requires minimal sample volume when screening iron status of premature infants $(9,10)$. Ratios are directly measured by clinical hematofluorometers on drops of blood with minimal cost $(34,35)$. Changes in $\mathrm{ZnPP} / \mathrm{H}$ are relatively specific, with lead poisoning, unlikely in newborns and hospitalized premature infants, raising ratios (19). In newborns, jaundice or pigmented drugs may artifactually elevate $\mathrm{ZnPP} / \mathrm{H}$, but simple rinsing removes plasma pigments (19). We found that reticulocyte enrichment step was reproducible and $\Delta \mathrm{ZnPP} / \mathrm{H}$ relatively more sensitive than whole blood $\mathrm{ZnPP} / \mathrm{H}$ in determining preanemic mild ID in newborn rats and humans. Four additional observations supported that $\Delta \mathrm{ZnPP} / \mathrm{H}$ was not artifact. First, the most common disturbance of red cell processing is hemolysis, but we observed that $\mathrm{ZnPP} / \mathrm{H}$ falls with hemolysis 
(unpublished data). Second, we mathematically projected that the bottom fraction $\mathrm{ZnPP} / \mathrm{H}$ would be unchanged after centrifugation and found that it was unchanged. Third, $\Delta \mathrm{ZnPP} / \mathrm{H}$ was unappreciable in normal term and preterm humans and adult rats. Fourth, immature erythrocytes comprise nearly all cells in the top fraction. Previous reports describe that adult whole blood also contains a very small percentage $(<0.1 \%)$ of low-density mature cells identified by resistance to shrinking with valinomycin (36). We treated neonatal cord blood with valinomycin to identify these mature low-density in the top fraction, but found scant numbers (data not shown).

Measuring whole blood and $\Delta \mathrm{ZnPP} / \mathrm{H}$ may minimize the disadvantage of developmental differences in whole blood $\mathrm{ZnPP} / \mathrm{H}$ in rats and humans minimize the overlap between normal and abnormal values and improve sensitivity in identifying mild ID. We speculate that identifying mild ID by $\Delta \mathrm{ZnPP} / \mathrm{H}$ when treating the anemia of prematurity could be clinically useful. Miller et al. showed that whole blood $\mathrm{ZnPP} / \mathrm{H}$ may respond to iron therapy (9), but by employing whole and $\Delta \mathrm{ZnPP} / \mathrm{H}$ would potentially improve the sensitivity to observe an iron response, and when iron dose is titrated to $\mathrm{ZnPP} / \mathrm{H}(9)$, avoid over treatment. Future work in this field is necessary.

Acknowledgments. The authors acknowledge experimental design support from John A. Widness, M.D and Richard Eisenstein, Ph.D., technical support by Elizabeth Goetz M.D., Debra Schneider B.S., Kelsey J. Kleven, and Aisha K. David. Also acknowledge engineering design from Undergraduates in Biomedical Engineering 201 students, Katy Reed, Sarajane Stevens, Christopher Westphal, and Anita Zarebi, with advisor Kristyn Masters, Ph.D.

\section{REFERENCES}

1. Meyer MP, Haworth C, Meyer JH, Commerford A 1996 A comparison of oral and intravenous iron supplementation in preterm infants receiving recombinant erythropoietin. J Pediatr 129:258-263

2. Brown MS 1996 Effect of transfusion and phlebotomy on serum ferritin levels in low birth weight infants. J Perinatol 16:39-42

3. Winzerling JJ, Kling PJ 2001 Iron deficient erythropoiesis in premature infants measured by blood zinc protoporphyrin/heme. J Pediatr 139:134-136

4. Juul SE, Zerzan JC, Strandjord TP, Woodrum DE 2003 Zinc protoporphyrin/heme as an indicator of iron status in NICU patients. J Pediatr 142:273-278

5. Labbé RF, Finch CA, Smith NJ, Doan RN, Sood SK, Madan N 1979 Erythrocyte protoporphyrin/heme ratio in the assessment of iron status. Clin Chem 25:87-92

6. Hastka J, Lasserre J-J, Schwarzbeck A, Hehlmann R 1994 Central role of zinc protoporphyrin in staging iron deficiency. Clin Chem 40:768-773

7. Rettmer RL, Carlson TH, Origenes ML, Jack RM, Labb RF 1999 Zinc protoporphyrin/heme ratio for diagnosis of preanemic iron deficiency. Pediatrics 104:e37

8. Lott DG, Zimmerman MB, Labbé RF, Kling PJ, Widness JA 2005 Erythrocyte zinc protoporphyrin is elevated with prematurity and fetal hypoxemia. Pediatrics $116: 414-422$
9. Miller SM, McPherson RJ, Juul SE 2006 Iron sulfate supplementation decreases zinc protoporphyrin to heme ratio in premature infants. J Pediatr 148:44-48

10. Kling PJ 2006 Zinc protoporphyrin/heme ratio in premature infants: has it found its place? J Pediatr 148:8-10

11. Brugnara C, Chambers LA, Malynn E, Goldberg MA, Kruskall M 1993 Red blood cell regeneration induced by subcutaneous recombinant erythropoietin: irondeficient erythropoiesis in iron-replete subjects. Blood 81:956-964

12. Brugnara C, Hipp MJ, Irving PJ, Lathrop H, Lee PA, Minchello EM, Winkelman J 1994 Automated reticulocyte counting and measurement of reticulocyte cellular indices. Evaluation of the Miles H*3 blood analyzer. Am J Clin Pathol 102:623-632

13. Brugnara C, Zurakowski D, DiCanzio J, Boyd T, Platt O 1999 Reticulocyte hemoglobin content to diagnose iron deficiency in children. JAMA 281:2225-2230

14. Ullrich C, Wu A, Armsby C, Rieber S, Wingerter S, Brugnara C, Shapiro D, Bernstein H 2005 Screening healthy infants for iron deficiency using reticulocyte hemoglobin content. JAMA 294:924-930

15. Bechensteen AG, Haga P, Halvorsen S, Liestol K, Lindemann R, Whitelaw A, Tollofsrud PA, Daae L, Thorstensen K, Sundal E 1997 Effect of low and moderate doses of recombinant human erythropoietin on the haematological response in premature infants on a high protein and iron intake. Eur J Pediatr 156:56-61

16. Rushing D, Vengelen-Tyler V 1987 Evaluation and comparison of four reticulocyte enrichment procedures. Transfusion 27:86-89

17. Dubuque SH, Dvorak B, Woodward SS, McCuskey RS, Kling PJ 2002 Iron deficient erythropoiesis in neonatal rats. Biol Neonate 81:51-57

18. Dvorak B, McWilliam DL, Williams CS, Dominguez JA, Machen NW, McCuskey RS, Philipps AF 2000 Artificial formula induces precocious maturation of the small intestine of artificially reared suckling rats. J Pediatr Gastroenterol Nutr 31:162-169

19. Hastka J, Lasserre JJ, Schwarzbeck A, Strauch M, Hehlmann R 1992 Washing erythrocytes to remove interferents in measurements of zinc protoporphyrin by front-face hematofluorometry. Clin Chem 38:2184-2189

20. Constandoulakis M, Kay HE 1959 Observations on the centrifugal segregation of young erythrocytes. J Clin Pathol 12:312-318

21. NCCLS 1996 Erythrocyte Protoporphyrin Testing: Approved Guideline (NCCLS Document C42-A). National Committee on Clinical Laboratory Standards, Villanova, PA, pp $1-40$

22. Aviv Biomedical 1993 Instruction Manual ZP Hematofluorometer Model 206D Aviv Biomedical, Lakewood NJ, pp 1-28

23. Lesser KB, Schoel SB, Widness JA, Kling PJ 2006 Elevated zinc protoporphyrin/ heme ratios in umbilical cord blood after diabetic pregnancies. J Perinatol 26:671676

24. Pearson HA 1967 Life-span of the fetal red blood cell. J Pediatr 70:166-171

25. Renton PH, Hancock JA 1964 A simple method of separating erythrocytes of different ages. Vox Sang 9:183-186

26. Koepke JF, Koepke JA 1986 Reticulocytes. Clin Lab Haematol 8:169-179

27. Petry CD, Eaton ME, Wobken JD, Mills MM, Johnson DE, Georgieff MK 1992 Iron deficiency of liver, heart, and brain in newborn infants of diabetic mothers. J Pediatr 121:109-114

28. Georgieff MK, Landon MB, Mills MM, Hedlund BE, Faassen AE, Schmidt RL, Ophoven JJ, Widness JA 1990 Abnormal iron distribution in infants of diabetic mothers: spectrum and maternal antecedents. J Pediatr 117:455-461

29. Kivivuori SM, Heikinheimo M, Teppo A-M, Siimes MA 1994 Early rise in serum concentration of transferrin receptor induced by recombinant human erythropoietin in very-low-birth-weight infants. Pediatr Res 36:85-89

30. Rusia U, Flowers C, Madan N, Agarwal N, Sood SK 1996 Serum transferrin receptor levels in the evaluation of iron deficiency in the neonate. Acta Paediatr Jpn 38:455-459

31. Kling PJ, Roberts RA, Widness JA 1998 Plasma transferrin receptor levels and indices of erythropoiesis and iron status in healthy term infants. J Pediatr Hematol Oncol 20:309-314

32. Monzon CM, Beaver BD, Dillon TD 1987 Evaluation of erythrocyte disorders with mean corpuscular volume (MCV) and red cell distribution width (RDW). Clin Pediatr (Phila) 26:632-638

33. Labbé RF, Dewanji A 2004 Iron assessment tests: transferrin receptor vis-a-vis zinc protoporphyrin. Clin Biochem 37:165-174

34. Labbé RF 1992 Clinical utility of zinc protoporphyrin. Clin Chem 38:2167-2168

35. Schifman RB, Rivers SL 1987 Red blood cell zinc protoporphyrin to evaluate anemia risk in deferred blood donors. Am J Clin Pathol 87:511-514

36. Bookchin RM, Etzion Z, Sorette M, Mohandas N, Skepper JN, Lew VL 2000 Identification and characterization of a newly recognized population of high- $\mathrm{Na}+$, Low-K+, low-density sickle and normal red cells. Proc Natl Acad Sci USA 97:8045-8050 